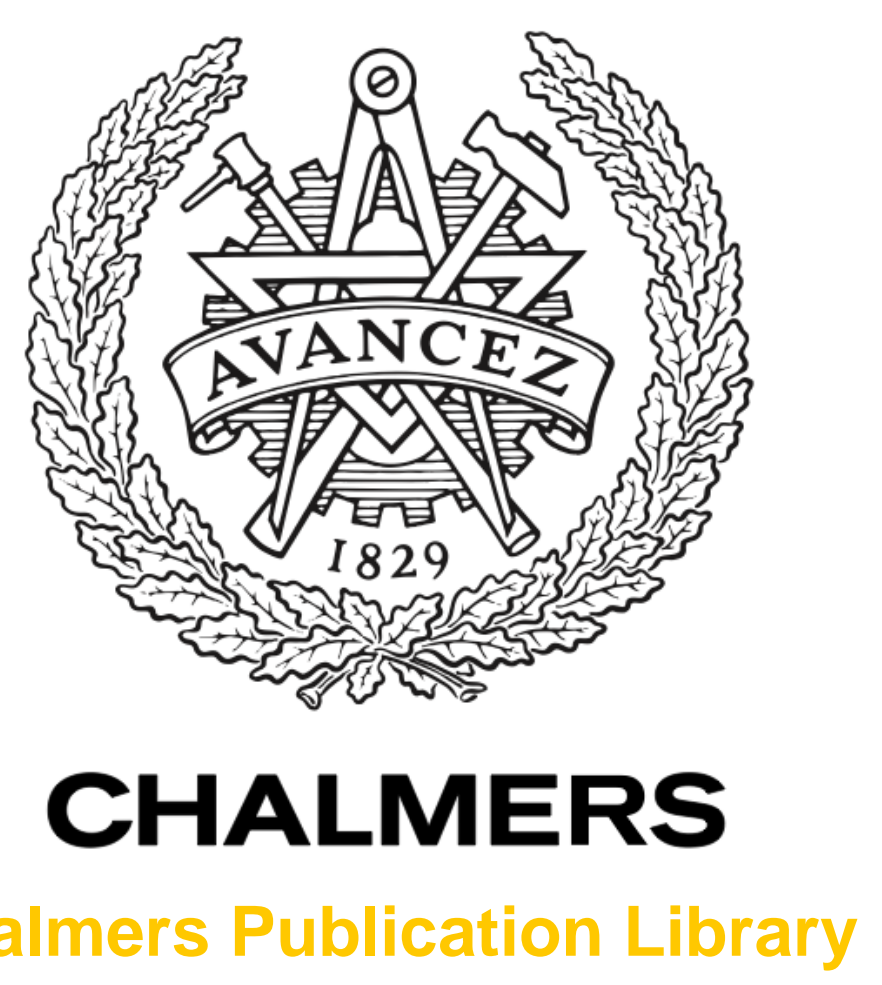

Chalmers Publication Library

\title{
Role of the aggregation behavior of hydrophobic particles in paper surface hydrophobation
}

This document has been downloaded from Chalmers Publication Library (CPL). It is the author's version of a work that was accepted for publication in:

Colloids and Surfaces A: Physicochemical and Engineering Aspects (ISSN: 0927-7757)

Citation for the published paper:

Iselau, F. ; Restorp, P. ; Andersson, M. et al. (2015) "Role of the aggregation behavior of hydrophobic particles in paper surface hydrophobation". Colloids and Surfaces A:

Physicochemical and Engineering Aspects, vol. 483 pp. 264-270.

http://dx.doi.org/10.1016/j.colsurfa.2015.04.013

Downloaded from: http://publications.lib.chalmers.se/publication/223424

Notice: Changes introduced as a result of publishing processes such as copy-editing and formatting may not be reflected in this document. For a definitive version of this work, please refer to the published source. Please note that access to the published version might require a subscription.

Chalmers Publication Library (CPL) offers the possibility of retrieving research publications produced at Chalmers University of Technology. It covers all types of publications: articles, dissertations, licentiate theses, masters theses, conference papers, reports etc. Since 2006 it is the official tool for Chalmers official publication statistics. To ensure that Chalmers research results are disseminated as widely as possible, an Open Access Policy has been adopted.

The CPL service is administrated and maintained by Chalmers Library. 


\section{Role of the aggregation behavior of hydrophobic particles in paper surface hydrophobation}

Frida Iselau ${ }^{1,2^{*}}$, Per Restorp ${ }^{2}$, Mats Andersson ${ }^{1}$, Romain Bordes $^{1 *}$

${ }^{1}$ Department of Chemistry and Chemical Engineering, Chalmers University of Technology, Göteborg, Sweden

${ }^{2}$ Akzo Nobel Pulp and Performance Chemicals AB, 44580 Bohus, Sweden

* To whom correspondence should be addressed.

Tel +46317722976.

E-mail addresses: frida.iselau@chalmers.se, bordes@chalmers.se.

\section{Abstract}

Three types of hydrophobic particles with different charge, i.e. cationic (SP+), anionic (SP-) and amphoteric (SPA) have been synthesized by emulsion polymerizations and evaluated in paper surface hydrophobation performance (frequently referred to as surface sizing). The surface sizing evaluation was done according to a well-established process, i.e. mixing of the particles with negatively charged starch followed by application in a conventional puddle size press using a fine paper grade containing calcium carbonate filler as model system. Prior to the application, the particles were characterized by light scattering and the surface charge was determined by particle charge density titrations and $\zeta$-potential measurements. The SP+ particles were determined to be $30 \mathrm{~nm}$ in diameter while SP- and SPA particles were around $65 \mathrm{~nm}$. Their colloidal behavior in the presence of anionic starch differed. The SP+ particles formed aggregates via bridging flocculation up to a charge ratio of 1:1 of starch:particles. At higher starch content the aggregates were partly redispersed. The SP- and SPA particles showed no sign of aggregation in the presence of anionic starch. In addition, the sizing performance of the different particles was evaluated by assessing the decrease of water uptake in a surface treated paper as well as water contact angle measurements on the paper surface. All three types of particles decreased the water penetration. However, the SP+/starch mixtures showed superior performance, which was attributed to a stronger sensitivity to the high electrolyte concentration usually found in the vicinity of the paper surface. 
Keywords: starch, hydrophobic particles, surface sizing, aggregation behavior, interactions. 


\section{Introduction}

In many applications a strong and water resistant paper material is required [1-4]. Due to the intrinsic hydrophilic character of the cellulosic fibers these paper grades are hydrophobically modified to reduce penetration and wetting of water. In the paper manufacturing industry this surface treatment is frequently referred to as sizing. Such a modification has historically been done on the wet-end of the paper machine where a hydrophobic moiety is added before the pulp is formed into a paper sheet and is forming covalent linkage to the cellulose chains [5-8]. This is usually referred to as internal sizing. For economic and environmental reasons, a shift is nowadays observed from internal sizing to surface sizing [9]. In surface sizing, the hydrophobizing agents are applied on the dry-end of the paper machine on the formed paper sheet and are mainly present at the paper surface where they are primarily needed. Surface sizing of fine paper grades is also important for good printability [10]. Surface sizing has the additional advantage of giving very pronounced retention [1,11-13] which is beneficial both from an economic and a process runnability point of view [1]. Technical reasons also favor surface sizing over internal sizing, for instance for recycled paper where the composition often varies, efficient internal sizing is often difficult to achieve [11].

In surface sizing the paper material is treated with a suspension of hydrophobic polymer particles in an anionic starch solution $[1,3,4,12]$. The starch enhances the paper stiffness by forming a film on the paper surface that creates strong hydrogen bonds with the cellulose fibers [13] and reduces the water penetration rate by filling in the surface voids in the paper sheet [1]. The hydrophobic polymer particles, typically a styrene-acrylate based copolymer, stabilized by amphiphiles of different natures $[2,4,14,15]$, render the paper surface hydrophobic $[1-3,16,17]$. The particle suspension is first mixed with the starch solution and the mixture is subsequently applied on the paper surface at the dry-end of the paper machine [18]. A pressure is applied and the paper is usually heated above the glass transition temperature of the polymer in order to promote coalescence of the colloidal layer [14]. There are different techniques to industrially apply the sizing agent on the surface of the paper, most prominently puddle press and film press [1]. In both techniques, the paper is first exposed to the particle:starch suspension to allow liquid absorption and adsorption to take place, and then, in a second step, exposed to an external pressure, the press step, and also afterwards, in a third step, the drying step. It is during the press and drying steps that the penetration of the sizing agent and the film formation is believed to occur.

Despite the fact that surface sizing is a well-established and efficient process, more knowledge regarding the surface size mechanism and the physical-chemical properties of the suspension that are important for an efficient process is needed. With an optimized efficiency of the sizing agents, paper materials can substitute part of the plastic packaging materials.

One key issue is the nature of the interaction between the polymer particles and the anionic starch. These components may form different types of complexes and the sizing efficiency is likely to be related to the nature of such complexes. 
In this work we have focused on the colloidal behavior of the hydrophobic polymer particles in presence of starch and on the role of the complexes formed for the sizing performance. To this end, cationic (SP+), anionic (SP-) and amphoteric particles (SPA), were prepared based on a hydrophobic core of a styrene-acrylate copolymer. The particles have been characterized with respect to size and surface charge and the interaction with anionic starch has been evaluated by turbidity, light scattering and $\zeta$-potential measurements. Finally, surface sizing tests have been carried out on a fine paper grade and the sizing efficiency has been assessed by means of contact angle and water uptake measurements.

\section{Materials and Methods}

\subsection{Materials}

Styrene (Sigma-Aldrich, $\geq 99 \%$ ), $n$-butyl acrylate (Sigma-Aldrich, $\geq 99 \%$ ), tert-butyl acrylate (Sigma-Aldrich $98 \%$ ), dodecanethiol (Sigma-Aldrich, $\geq 98 \%$ ), sodium chloride ( Merck $\geq 99.5 \%$ ), hydrogen peroxide (Eka HP G59), iron-(II)-sulphate (Sigma-Aldrich $99 \%$ ), glacial acetic acid (Merck, $\geq 99.8 \%$ ) and sodium hydroxide (Merck, $99 \%$ ) were used as purchased.

The synthetic cationic emulsifier, a copolymer of styrene and a mixure of quaternary ammonium compounds was supplied by AkzoNobel Pulp and Performance Chemicals, Spain. The composition and synthesis route is comparable with the description in the US Patent US2008/0039598.

The starch based emulsifiers were prepared from an oxidized potato starch and a cationized potato starch (D.S. 0.035), both from Avebe, Holland. The oxidized starch was also used for the surface sizing application test.

Milli-Q water (resistivity > $18 \mathrm{M} \Omega$ ) was used for the preparation of aqueous solutions. For the particle charge density titrations solutions of $0.001 \mathrm{~N}$ polydiallyldimethyl ammonium chloride (polyDADMAC) and $0.001 \mathrm{~N}$, sodium polyethylene sulphonate (PES-Na) from BTG Instruments $\mathrm{AB}$ as well as hexadimethrine bromide (polybrene) from Sigma-Aldrich ( $\geq 95 \%)$ were used.

The test paper that was used in the sizing efficiency assessment was a fine paper grade produced on a pilot paper machine at the Technical University of Munich. The composition of the fine paper grade was chemical pulp with a filler content of ground calcium carbonate (GCC) corresponding to an ash content of 16-18\%. AKD (alkyl ketene dimer) was used as internal sizing agent and a cationic starch from Roquette with a DS of 0.03 was used for mechanical strength enhancement.

\subsection{Methods}




\subsubsection{Preparation of the anionic and amphoteric emulsifiers}

The starches used in the emulsion polymerization of the anionic and amphoteric particles were first degraded to lower viscosity using a double-jacketed reactor. The oxidized starch was cooked for 2 hours and the cationized starch was cooked for 4 hours in order to reach the same target viscosity. The starch cooking was performed at $95^{\circ} \mathrm{C}$ and the starch was oxidized by a redox system comprising hydrogen peroxide/iron-(II)- sulphate. The starches were degraded to a final viscosity of 3-4 mPa.s measured at $25^{\circ} \mathrm{C}$ and with $12.5 \%$ dry content. The $\mathrm{pH}$ of the starch was adjusted by adding acetic acid and $\mathrm{NaOH}$ to $\mathrm{pH} 4.0$.

\subsubsection{Synthesis of hydrophobic particles, SP+, SPA and SP-} Approximately $300 \mathrm{~g}$ of the emulsifier solution (dry content of $12.5 \%$ ) was preheated to $68{ }^{\circ} \mathrm{C}$ in a double jacketed reactor and the iron-(II)-sulphate was added to the reactor. The radical polymerization was initiated by the redox system hydrogen peroxide and iron-(II)sulphate in an emulsion polymerization reaction with a feed monomer process.

The monomers (50 wt \% styrene, $45 \mathrm{wt} \%$ tert-butyl acrylate, $5 \mathrm{wt} \% n$-butyl acrylate) with $0.36 \mathrm{wt} \%$ dodecanethiol were dosed into the reactor during 3 hours using a Dosimat (Metrohm) with the addition rate of $0.36 \mathrm{~mL} / \mathrm{min}$ to a total amount of $57.6 \mathrm{~g}$. Simultaneously $8.57 \mathrm{~mL}$ of a $35 \mathrm{wt} \%$ hydrogen peroxide solution was added during 3.5 hours with a dosing speed of $0.04 \mathrm{~mL} / \mathrm{min}$. After 4.5 hours reaction time the suspension was cooled to room temperature. After cooling the $\mathrm{pH}$ was adjusted to 3.6.

\subsubsection{Particles characterization}

\subsubsection{Dynamic Light Scattering}

A Malvern Nano instrument was used for measuring the particle size by dynamic light scattering. The samples were prepared by suspending the particles in $1 \mathrm{mM} \mathrm{NaCl}$ solution to a concentration of $0.05 \mathrm{wt} \%$. Samples were filtrated with $0.2 \mu \mathrm{m}$ hydrophilic syringe filter (Sartorius) before each measurements.

\subsubsection{Zeta potential}

The Zeta potential was measured using a Malvern Nano instrument and disposable measuring cells. The samples were prepared by suspending the particles in $1 \mathrm{mM} \mathrm{NaCl}$ solution to a concentration of $0.05 \mathrm{wt} \%$. Samples were filtrated with $0.2 \mu \mathrm{m}$ hydrophilic syringe filter (Sartorius) before measurements.

\subsubsection{Particle charge density titration}

Particle charge density titration was performed with oppositely charged polymers using a Particle Charge Detector, CAS Charge Analyzing System (AFG, Analytic GMBH). For the anionic particles the titration was performed using polyDADMAC and for the amphoteric and cationic particles the titration was performed with PES-Na. The anionic starch was titrated with polybrene.

\subsubsection{Glass transition temperature}


The glass transition temperature was measured with a DSC Star System instrument (Mettler Toledo). The particle suspensions were casted onto glass slides and let to dry for six days at room temperature. The DSC measurements were done with repeating cycles of heatingcooling. Heating and cooling rate between $10^{\circ} \mathrm{C}$ and $150^{\circ} \mathrm{C}$ were $10^{\circ} \mathrm{C} / \mathrm{min}$. The glass transition temperature was taken at the onset of the curve during the heating process.

\subsubsection{Paper characterization}

The chemical composition of the fine paper grade was determined with ESCA. The contact angle of the paper grade was also measured. The colloidal charge was determined with PCD on a slurry of disintegrated paper.

\subsubsection{Chemical composition}

ESCA was used to determine the chemical composition of the paper surface. From the test paper sheets small paper pieces were cut and stored in glass containers before measurement to prevent the surfaces from contamination.

\subsubsection{Air permeability and roughness}

The air permeability and roughness were measured using a Bendtsen equipment where pressurized air is flowed through the paper sheet for determination of air permeability and along the paper surface for determination of roughness measurements. The air permeability is dependent on the paper thickness.

\subsubsection{Contact angle}

The contact angle measurements were performed using a DAT 1100 (Fibro System AB). From each test paper sheet three stripes were cut out and the contact angle of eight droplets (each $4 \mu \mathrm{l}$ MilliQ water) on each stripe was measured.

\subsubsection{Colloidal charge of fiber slurry}

To measure the colloidal charge of the fiber slurry approximately $30 \mathrm{~g}$ of paper sheets were grated and added to $2000 \mathrm{~mL}$ deionized water and let to swell for two hours. The swelled paper fragments were then defibrillated using a blender. Afterwards the dry content was measured and the slurry was diluted to a final concentration of $4 \mathrm{~g} / \mathrm{l}$. The fibre charge was measured with PCD. The $\mathrm{pH}$ of the slurry was measured before and after titration. As titrand polyDADMAC $0.001 \mathrm{~N}$ was used.

\subsubsection{Cobb60}

The surface sizing performance was evaluated with the Cobb60 method according to TAPPI Method T-441. In short it is a weight water pick-up test where $100 \mathrm{~mL}$ of deionized water is applied onto a $100 \mathrm{~cm}^{2}$ area of the paper surface during 60 seconds using a retaining ring that is clamped on top of the paper. After 60 seconds the excess of water is removed and the water uptake is measured as a weight increase of the paper sheet. [14] . 


\subsubsection{Surface sizing}

The oxidized starch solution that was used for the size press evaluation was prepared in a jet batch cooker where high temperature, high pressure and high shear forces from the steam gives a fully hydrated starch in solution [19]. The final starch solution was held at approximately $70{ }^{\circ} \mathrm{C}$ during storage to prevent retrogradation [1] and around $60{ }^{\circ} \mathrm{C}$ when used in the size press. The hot starch solution was added to a specific amount of the hydrophobic particle suspension and the mixture was diluted to a final concentration of $8 \%$ starch and 0.02-0.2 \% particles. The mixture was then applied in the lab size press equipment from Mathis AG. During application the liquid temperature was held above $60{ }^{\circ} \mathrm{C}$. The roll speed was $1.8 \mathrm{~m} / \mathrm{min}$ and the roll pressure was $2 \mathrm{~kg} / \mathrm{cm}^{2}$. The surface sized paper sheets were dried in a contact dryer held at $80{ }^{\circ} \mathrm{C}$. The surface sized paper sheets were then placed in a climate room with a temperature of $23^{\circ} \mathrm{C}$ and relative humidity of $50 \%$ over night. The hydrophobic resistance was evaluated after $24 \mathrm{~h}$ by the Cobb60 test method. A Cobb60 value of $30 \mathrm{~g} / \mathrm{m}^{2}$ and below is regarded as a sufficiently surface sized paper.

\subsubsection{Turbidity}

The turbidity measurements were performed on an Agilent Cary $60 \mathrm{UV} / \mathrm{V}$ is instrument using a quartz cuvette. The baseline was recorded in MilliQ water. The value of the absorbance at $400 \mathrm{~nm}$ was used as a measure of the turbidity. The samples were filtered before measurement using a Minisart $0.2 \mu \mathrm{m}$ filter before $2 \mathrm{~mL}$ sample was transferred to the cuvette. The titrations were carried out as follows. To $2 \mathrm{~mL}$ sample in a cuvette $20 \mu \mathrm{L}$ aliquots of a $3 \mathrm{wt} \%$ starch solution were successively added. After each addition the cuvette was shaken vigorously before put into the instrument for measurements.

In addition, measurements were performed under stirring. A beaker with $20 \mathrm{~mL}$ of filtered sample of $0.1 \mathrm{wt} \%$ particle suspension was put on a magnetic stirrer plate. $500 \mu \mathrm{l}$ aliquots of a $3 \mathrm{wt} \%$ starch solution were successively added to the vortex of the particle suspension. After a mixing time of 30 seconds a $2 \mathrm{~mL}$ sample was taken from the mixture and transferred to the cuvette for UV/Vis measurement. After the measurement the $2 \mathrm{~mL}$ sample was returned to the beaker and a new addition of starch was done. Finally the importance of the order of addition was assessed. To $1 \mathrm{~mL}$ starch with increasing concentrations $1 \mathrm{~mL}$ of $0.2 \mathrm{w} \%$ particle suspension was added yielding a final concentration of $0.1 \mathrm{w} \%$ particles. To be able to compare with the results where starch was added to the $2 \mathrm{~mL}$ particle suspension water was added to compensate for the dilution.

\section{Results and discussion}

\subsection{Synthesis and charaterization of the sizing suspensions}

\subsubsection{Synthesis}

The surface sizing particles in this study consist of a hydrophobic core of a styrene-acrylate copolymers. Colloidal stability is achieved by a cationic, anionic or amphoteric stabilizer, as illustrated in Figure 1. The cationic stabilizer used in this study is a copolymer of styrene and 
quaternary ammonium monomers. The anionic and amphoteric stabilizers are starch-based materials (oxidized or cationizied respectively) where the starch first was first oxidatively degraded by the redox system hydrogen peroxide/iron-(II)-sulphate.

The radical polymerization was carried out as an emulsion polymerization in the presence of the stabilizer (degraded starch or synthetic copolymer). The polymerization was initiated by the hydrogen peroxide in presence of iron-(II)-sulphate that acts as a catalyst for formation of radicals. To control the molecular weight, dodecanethiol was used as a chain transfer agent. The anionic charges of the starch-based stabilizers are due to the carboxylic groups from the oxidation reaction of starch carried out prior to the polymerization.
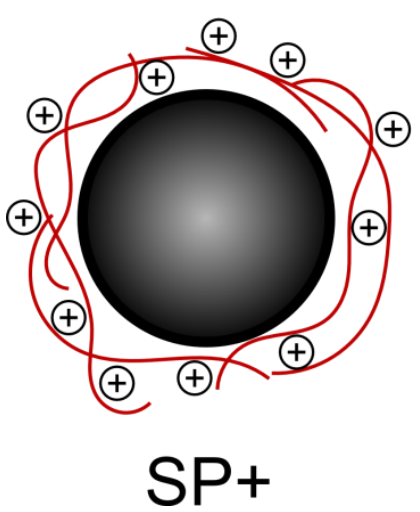
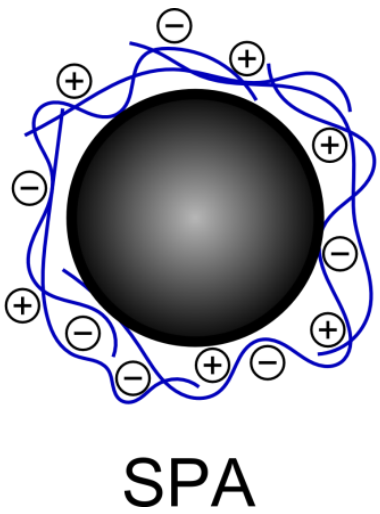
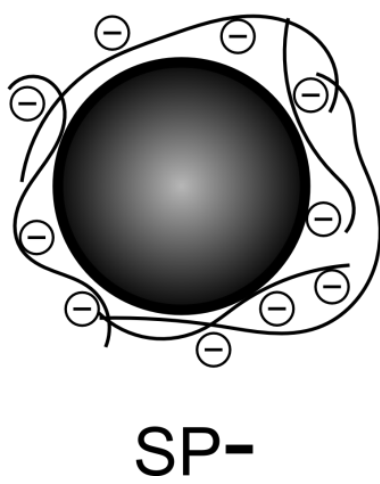

Figure 1. Schematic representation of the particle system used in this study.

\subsubsection{Characterization of the colloidal suspensions}

The particle size, the $\zeta$-potential and the results from the particle charge density titrations of the three batches are listed in Table 1. As can be seen, the particles prepared in the presence of the starch based stabilizers have similar sizes, close to $65 \mathrm{~nm}$. The $\zeta$-potential and the surface charge determined by titration (PCD) are in agreement with expectations. SP- carries a net negative charge resulting from the oxidized groups on the degraded starch. The amphoteric emulsifier carries cationic charges from the quaternary ammonium groups on the starch and anionic charges from the oxidation of the starch during the degradation step. The SPA particle is therefore almost net neutral. A slight difference can be noted between the $\zeta$ potential measurements and the PCD, which can be attributed to the measurements conditions since the $\zeta$-potential is measured in a $1 \mathrm{mM} \mathrm{NaCl}$ solution while the PCD titration is performed in deionized water.

The $\mathrm{SP}+$ particles prepared with the cationic synthetic emulsifier are somewhat smaller, around $30 \mathrm{~nm}$. PCD and $\zeta$-potential measurements on the SP+ particles show a pronounced positive surface charge, which is due to the adsorbed cationic stabilizer onto the hydrophobic core moity.

Also given in the table 1 is the PCD of the starch that is used in combination with the particles on the paper surface. Its charge density of $-220 \mu \mathrm{eq} / \mathrm{g}$, is due to oxidation. 
Table 1 . Hydrodynamic diameter, $\zeta$-potential, surface charge and glass transition temperature of the synthesized sizing agents. The surface charge of the starch is also given.

\begin{tabular}{|c|c|c|c|c|}
\hline & $\begin{array}{l}\text { Particle } \\
\text { diameter }(\mathrm{nm})\end{array}$ & $\zeta$-potential $(\mathrm{mV})$ & $\begin{array}{l}\mathrm{PCD} \\
\text { titration } \\
(\mu \text { eq/g) }\end{array}$ & $\mathrm{Tg}\left({ }^{\circ} \mathrm{C}\right)$ \\
\hline SPA & 65 & -2 & 8 & 73.3 \\
\hline SP- & 69 & -29 & -60 & 73.7 \\
\hline SP+ & 31 & 45 & 560 & 70.2 \\
\hline Starch & NA & NA & -220 & NA \\
\hline
\end{tabular}

The glass transition temperature for the three particle batches is also listed in Table 1. Regardless of the synthesis path, the values obtained are around $70{ }^{\circ} \mathrm{C}$. This is important since the glass transition temperature deeply influences the hydrophobic core content upon heating which in turn can affect the sizing efficiency.

\subsection{Colloidal behavior}

During the sizing process the particles are mixed with starch. The starch contributes to the paper stiffness [13] and decreases the rate of water uptake by providing a smoother surface. The starch and the paper fiber are usually negatively charged [20] while the charge carried by the hydrophobic particles can be tailored. In addition, fillers such as calcium carbonate can be found in the paper composition, giving the system a more complex behavior. Calcium carbonate is often regarded as a semi-soluble mineral and has a charge surface that is highly dependent on the $\mathrm{pH}$. Understanding the nature of the complex formed by starch and the particles constitutes one of the keys to interpret the adsorption behavior at the fiber surface. The interaction study presented here has focused on the colloidal behavior of the combination of particles and anionic starch. The three particle suspensions at $0.1 \mathrm{wt} \%$ were titrated with the anionic starch and the interactions were monitored by following the turbidity of the suspension with a spectrophotometer at $400 \mathrm{~nm}$.

Figure 2 shows the turbidity of the suspension of SP+, SPA and SP-plotted against starch concentration. As shown in Figure 2, the behavior of SPA and SP- is almost identical. A minor, but constant, decrease of turbidity is visible at high starch concentrations which can be attributed to the small dilution of the particles upon addition of the starch solution. 


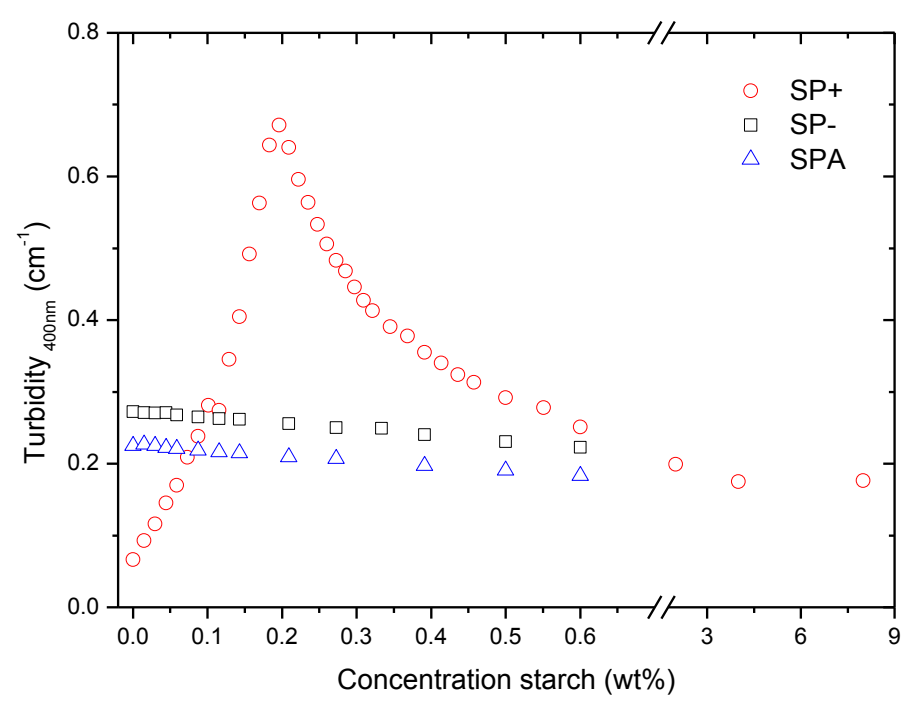

Figure 2. Turbidity as a function of starch concentrations for the three types of sizing particles, cationic (SP+), anionic (SP-) and amphoteric (SPA). Note the break in the scale.

The addition of starch to the cationic particle suspension gives results that deserve special attention. First, the addition of starch induces a dramatic increase in turbidity due to formation of aggregates in the system, most likely as a result of bridging flocculation. The aggregation of charged particles by oppositely charged polyelectrolytes has been reported in many studies $[2,21]$. However, further addition of starch partially restores the stability of the dispersion; this can be seen by the decrease in turbidity above $0.2 \mathrm{wt} \%$ starch concentration. At a starch concentration of $8 \mathrm{wt} \%$, corresponding to the application conditions, the turbidity of the combination of the cationic particles and starch is still higher than the initial value. Furthermore, the complex is then negatively charged with a $\zeta$-potential of $-8 \mathrm{mV}$. Interestingly, maximum turbidity is obtained for a charge ratio of 1:1 between starch and the cationic particles.

A number of reference experiments were done in order to investigate if mixing rate or addition order would have an impact on the formed aggregates of SP+ and starch and it was found that the same aggregation behavior was achieved irrespective of how the SP+ particles and starch were mixed.

\subsection{Paper hydrophobation efficiency}

The sizing efficiency of the starch/particles mixtures was evaluated by applying the hydrophobic particles in combination with starch on a model surface consisting of a fine paper grade with a grammage of $80 \mathrm{~g} / \mathrm{m}^{2}$. Fine paper grades often contain fillers and are typically internally sized with agents such as alkyl ketene dimer or alkyl succinic anhydride $[6,10]$. The sizing mixture was applied on the paper surface using a size press equipment where the starch/particles mixtures at different particle concentrations were poured between 
two rotating rolls forming a pond. The test papers were placed in this pond and were transported through the solution by the counter rotating rolls, as shown in Figure 3. The temperature of the solution in the pond was around $60^{\circ} \mathrm{C}$. With this application technique the test papers are first exposed to the liquid for a relatively short time during which absorption and adsorption occurs. Then the starch/particles mixture is pressed into the paper sheet by the rolls allowing further penetration. This pressing process is fast and takes only a couple of seconds. The test papers were then placed in a contact dryer and dried at $80{ }^{\circ} \mathrm{C}$. The efficiency in terms of reduced water uptake was measured after $24 \mathrm{~h}$ equilibration in a controlled climate room. The dosage used for sizing ranged from $0.015 \mathrm{wt} \%$ to $0.2 \mathrm{wt} \%$ in the sizing bath for SP- and SPA and 0.015 to $0.08 \mathrm{wt} \%$ for SP+. The starch concentration was kept at $8 \mathrm{wt} \%$.

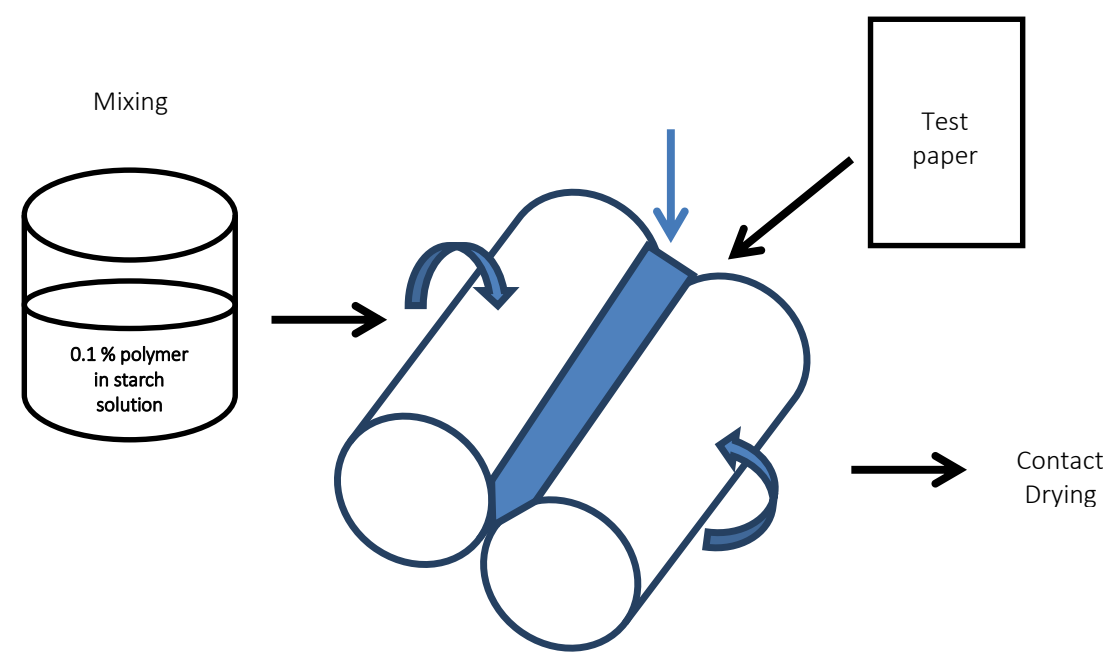

Figure 3. Schematic representation of the sizing equipment used to apply the starch/particles suspension.

Throughout the study, the paper properties were assessed in terms of porosity, water uptake and contact angle. Prior to the measurements, the charge and chemical composition of the paper were determined.

\subsubsection{Paper composition}

The chemical composition of the paper sheet surface as determined by ESCA is summarized below (Table 2). As comparison the composition of filter paper made of pure cellulose is included in the table. The fine paper has similar elementary composition as the pure cellulose filter paper except from the calcium content that comes from the calcium carbonate used as filler. The carboxylic content of the paper, originating from the anionic nature of the paper surface [20], was determined by deconvolution of the carbon peak in the spectrum. The 
results shown in the table demonstrate the presence of carboxylic groups in different amounts, the fine paper carrying a higher charge.

Even though it is well established that cellulose fibers carry a net negative charge, the situation can be different when looking at the processed paper surface. In the present case, calcium carbonate is introduced in the form of microparticles $(1-2 \mu \mathrm{m})$. Under the $\mathrm{pH}$ conditions of the sizing tests, close to $\mathrm{pH} 5$, the calcium ions can be partly solubilized. In addition, salts left from the process can also be present. The balance of the electrostatic interactions is therefore not easy to predict and the sizing performance, which is predominantly based on the adsorption of starch and particles, is very difficult to anticipate.

Table 2. Chemical composition of the fine paper used for the sizing test compared to filter paper. As comparison, the composition of regular filter paper made from pure cellulose is given. The table also contains values of surface charge of the fiber suspension.

\begin{tabular}{|c|c|c|c|c|c|c|c|c|}
\hline Paper quality & $\begin{array}{c}C \\
(\%)\end{array}$ & $\begin{array}{c}\mathbf{O} \\
(\%)\end{array}$ & $\begin{array}{c}\text { Ca } \\
(\%)\end{array}$ & $\begin{array}{l}\text { C-C } \\
(\%)\end{array}$ & $\begin{array}{c}\text { C- } \\
\mathbf{O} \\
(\%)\end{array}$ & $\begin{array}{c}\text { O- } \\
\text { C-O } \\
\text { or } \\
\mathrm{C}=\mathrm{O} \\
(\%)\end{array}$ & $\begin{array}{c}\text { O- } \\
\mathrm{C}=\mathbf{O} \\
(\%)\end{array}$ & $\begin{array}{l}\text { Charge } \\
\mu \mathrm{ekv} / \mathrm{g}\end{array}$ \\
\hline Filter paper & 54.7 & 45.7 & 0 & 3.6 & 74.9 & 19.5 & 2.0 & - \\
\hline Fine paper & 55.7 & 41.0 & 3.3 & 25.2 & 52.6 & 14.7 & 7.5 & -5.1 \\
\hline
\end{tabular}

\subsubsection{Permeability of the paper}

The air permeability and roughness were measured using Bendtsen equipment. This empirical method is based on an air leakage technique where the flow directly correlates with the roughness and porosity. Typically, a low flow indicates that the paper surface is smooth while a high flow is a sign of roughness.

The papers tested were sized with the highest dosage, corresponding to $0.2 \mathrm{wt} \%$ dosage for SPA, $0.15 \mathrm{wt} \%$ of SP- and with $0.08 \mathrm{wt} \%$ dosage for SP+. In addition the effect of starch on the surface properties of the paper was assessed. The results are shown in Table 3 where it can be seen that the air permeability decreases when the starch is applied on the surface. A reasonable explanation for this is that applied starch on the paper surface fills the surface voids in the paper sheet [1]. No additional decrease in air permeability can be seen when the combination of starch and the particles was applied on the paper surface. Previous studies of surface topography on similar systems confirms that surface sizing particles is not affecting the surface structure [22]. The roughness is not affected by this surface treatment since the untreated paper sheets have a smooth surface due to the high filler content [10]. 
Table 3. Air permeability and roughness determined by air leakage measurements on the top surface of the paper. The particle concentration was the highest dosage used in the water retention test. The systematic error is $\pm 15 \mathrm{~mL} \cdot \mathrm{min}^{-1}$.

\begin{tabular}{|c|c|c|}
\hline Fine paper & $\begin{array}{c}\text { Air permeability, } \\
\mathrm{mL} / \mathrm{min}\end{array}$ & $\begin{array}{c}\text { Roughness, } \\
\mathrm{mL} / \mathrm{min}\end{array}$ \\
\hline Untreated & 390 & 370 \\
\hline With starch & 320 & 380 \\
\hline SP- & 330 & 330 \\
\hline SPA & 340 & 390 \\
\hline SP+ & 330 & 340 \\
\hline
\end{tabular}

\subsubsection{Water retention}

The sizing performance was evaluated by Cobb60 measurements. This method is a straightforward test that is carried out by exposing the sized paper to water for 60 seconds. The water is then quickly removed and the water uptake is measured as the increase of mass and normalized to the surface exposed.

The non-sized paper had a water uptake of $81 \mathrm{~g} \cdot \mathrm{m}^{-2}$. After exposition to starch at a concentration of $8 \mathrm{wt} \%$, the water uptake increased to $107 \mathrm{~g} \cdot \mathrm{m}^{-2}$, which is an indication of a more hydrophilic paper surface, as observed in previous studies [18, 22].

Figure 4 shows the results of a Cobb60 test for the three types of particles on a model fine paper using an increasing concentration of sizing particles while the starch concentration remained at $8 \mathrm{wt} \%$.

From this figure two different patterns can be observed. The batches SP- and SPA had low sizing efficiency even at high particle dosage, yielding high water uptake. SP-gave the highest water uptake through the entire test series. SP+ behaved differently and showed an interesting pattern. First, the Cobb60 value decreased rapidly when the amount of sizing agent was increased and it came down to a low Cobb value of $26 \mathrm{~g} \cdot \mathrm{m}^{-2}$. At the same particle loading, the Cobb60 values for SPA and SP- were much higher, around 70-80 g.m $\mathrm{m}^{-2}$. For the SPA particles the added amount of $0.2 \mathrm{wt} \%$ gives the same Cobb60 value as a dosage of 0.04 $\mathrm{wt} \%$ of $\mathrm{SP}+$.

A tentative explanation of this difference in behavior is the following. For all three particle types the particles were blended with an excess of negatively charged starch. Only in the case of SP+, a strong interaction took place between the starch and the particles, yielding stable complexes at high starch concentration. With SP- and SPA there was no or little interaction. When the paper is exposed to water, the electrolyte concentration in the vicinity of the paper surface increases, due to solubilization of entrapped salts during the paper making process. This high electrolyte concentration promotes more predominantly the precipitation of the $\mathrm{SP}+/$ starch complex, resulting in a higher loading of hydrophobic particles on the paper surface. In the case of SP- and SPA, starch and particles remain in solution. This hypothesis is currently under investigation and will be the topic of a separate publication. 


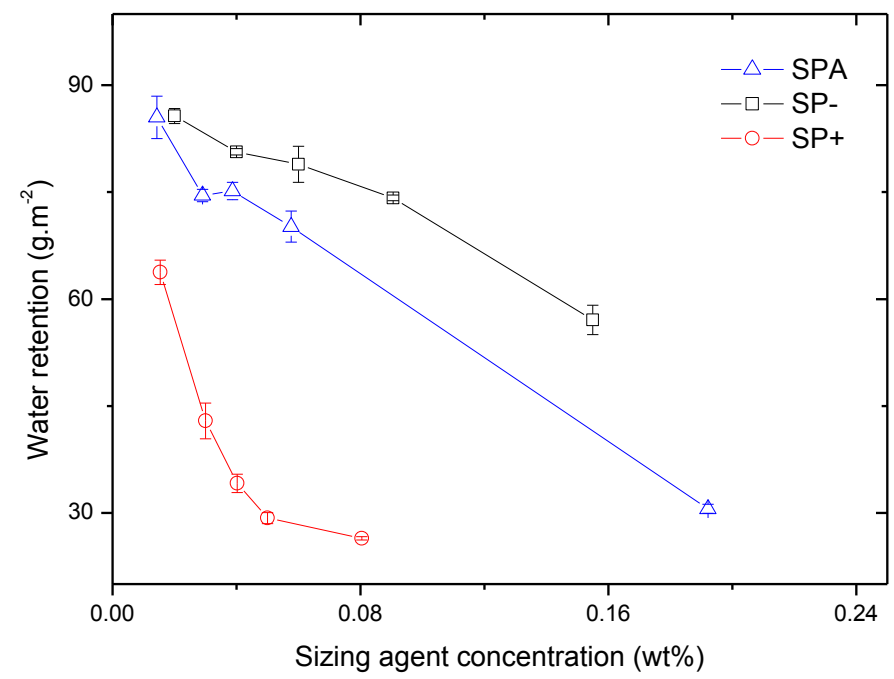

Figure 4. Water retention as determined by the Cobb60 test as a function of surface sizing particle concentration in $8 \mathrm{wt} \%$ starch solution.

\subsubsection{Contact angle}

The contact angle of water on the surface sized paper sheets as a function of time is shown in figure 5. For comparison, an untreated paper sheet was also included. The contact angle values for the untreated paper was quite high, around $60^{\circ}$ after $5 \mathrm{~s}$, considering the natural hydrophilicity of the cellulosic fibers. However, the hydrophobic character of the pulp treated with $\mathrm{AKD}$ during the paper formation could be a reasonable explaination for this.

When starch was applied onto the paper surface, the contact angle decreased. This has been seen in previous studies [18,22]. This is expected since starch is hydrophilic and applied on the paper surface mainly for increasing surface strength. In addition, in the paper making process, starch is applied on the paper surface in order to decrease the surface roughness and thereby decrease the rate of water uptake. However, this could not be seen here as the penetration rates, reflected by the decrease of contact angle, of untreated paper and paper treated by starch were the same. This was also confirmed by the surface roughness measurements done by the air leakage technique.

The application of the hydrophobic particles at $0.06 \mathrm{wt} \%, 0.06 \mathrm{wt} \%$ and $0.05 \mathrm{wt} \%$ for SP-, $\mathrm{SPA}$, and $\mathrm{SP}+$, respectively, in combination with starch, raised the contact angle in the order $\mathrm{SP}+>\mathrm{SPA}>\mathrm{SP}-$. This order is relatively in agreement with the results from the Cobb60 tests and confirms the better performance of SP+ as compared to the anionic SP- and the amphoteric SPA analogue. In addition, the application of the sizing agent reduced the penetration rate of water. 


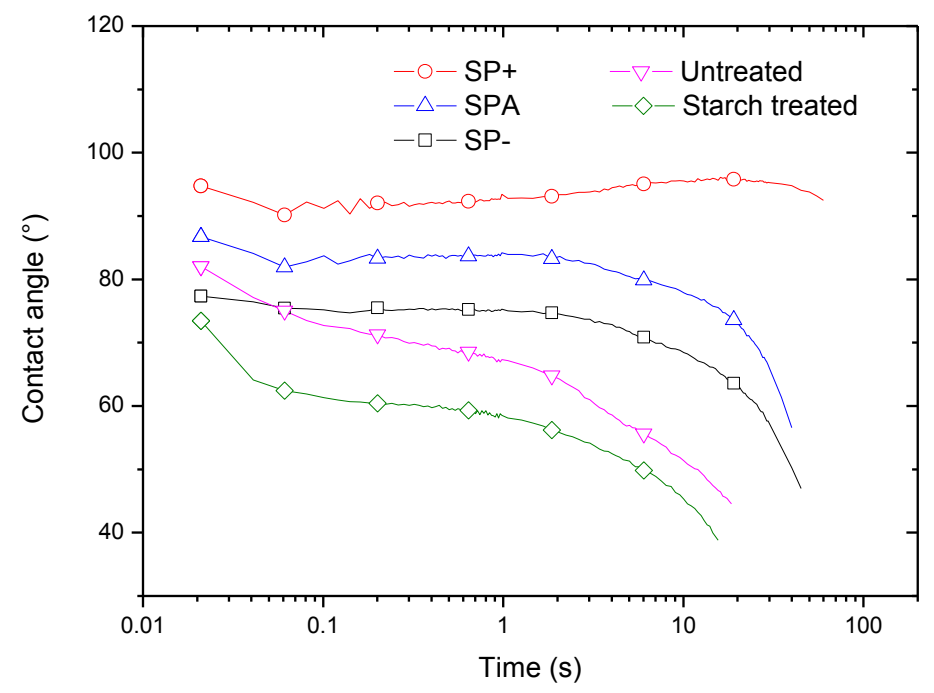

Figure 5. Contact angle as function of time of $4 \mu \mathrm{L}$ water droplet deposited on the sized paper sheet. Untreated paper was used as reference.

\section{Conclusion}

In this works we have studied the role of the interaction between starch and hydrophobic particles for surface sizing. The particles used for this purpose were synthesized in an emulsion polymerization process and they differed mainly with respect to surface charge, owing to the cationic, anionic and amphoteric nature of the emulsifier employed. The hydrophobic core of the particles was the same: a copolymer of styrene and butyl acrylate.

We have shown that, in presence of negatively charged starch, SP+ forms aggregates with the starch, most likely via bridging flocculation up to a charge ratio of negative starch to positive particles of 1:1. Above this ratio, the colloidal stability was partially restored, leading to starch stabilized complexes. In contrast, the SP- and SPA particles did not form large complexes with starch.

The sizing performance on a model paper grade of the starch/particles mixtures was assessed by means of permeability and roughness measurements, determination of water retention capacity and contact angle measurements of water on the paper surface. The model paper grade used contains ground calcium carbonate as filler. The air permeability was much affected by the starch addition and the presence of particles had only a marginal effect on the paper permeability.

In addition, for the three types of particles a sizing effect was observed, and the effect was confirmed by contact angle measurements. Interestingly, the sizing performance could be correlated with the aggregation behavior, demonstrating a high sizing capacity of the complexes formed by cationic particles and starch. Furthermore, the behavior of the 
complexes in presence of salt could be a key to understand the details of the mechanism of the sizing process.

\section{Acknowledgement}

Financial support from the Swedish Research Council is gratefully acknowledged.

Anne Wendel, Chalmers University of Technology, is acknowledged for performing the ESCA analyses.

\section{References}

[1] C.P. Klass, XIII Suface Sizing, Pulp and Paper Manufacture 17 (1991) 306-322.

[2] C.M. Andersson, L. Järnström, Controlled penetration of starch and hydrophobic sizing agent in surface sizing of porous materials, Appita Journal, 59 (2006) 207-212.

[3] I.M.T. Moutinho, A.M. Kleen, M.M.L. Figueiredo, P.J.T. Ferreira, Effect of surface sizing on the surface chemistry of paper containing eucalyptus pulp, Holzforschung, 63 (2009) 282-289.

[4] J. Xu, H. Hu, Preparation and characterization of styrene acrylate emulsion surface sizing agent modified with rosin, Journal of Applied Polymer Science, 123 (2012) 611-616.

[5] N. Yang, Y. Deng, Paper sizing agents from micelle-like aggregates of polystyrene-based cationic copolymers, Journal of Applied Polymer Science, 77 (2000) 2067-2073.

[6] T. Lindström, H. O'Brian, On the mechanism of sizing with alkylketene dimers. Part 2., Nordic Pulp and Paper Research Journal, 1 (1986) 34-42.

[7] M.A. Hubbe, Puzzling aspects of the hydrophobic sizing of paper and its inter-fiber bonding ability, BioResources, 9 (2014) 5782-5783.

[8] G. Garnier, J. Wright, L. Godbout, L. Yu, Wetting mechanism of alkyl ketene dimers on cellulose films, Colloids and Surfaces A: Physicochemical and Engineering Aspects, 145 (1998) 153-165.

[9] S. Iwasa, Advanced surface sizing of newsprint for offset lithography, in: Scientific \& Technical Advances in the Internal \& Surface Sizing of Paper \& Board, Prague, 2001. [10] B.-U. Cho, G. Garnier, Effect of the paper structure and composition on the surface sizing pickup, TAPPI Journal, 83 (2000) 60.

[11] J. Anderson, Surface Sizing, in: I.T. J. Brander (Ed.) Surface Application of Paper Chemicals, Springer Science \& Business Media, London, 1997, pp. 138-155.

[12] B.W. Ranson, New surface size option maintains performance, lessens internal sizing, Pulp and Paper, 78 (2004) 50-54.

[13] R.T. Gray, D.S. Rende, Surface Sizing, in: J.M.R. Jerome M. Gess (Ed.) The Sizing of Paper, Tappi Press, Atlanta, 2005, pp. 257-286.

[14] J. Sajbel, Surface Sizing Additives, in: J.M.R. Jerome M. Gess (Ed.) The Sizing of Paper, Tappi Press, Atlanta, 2005, pp. 287-300.

[15] R. Exner, Synthesis and application of polymer sizing agents, Paper Technology, 43 (2002) 45-51.

[16] I.M.T. Moutinho, P.J.T. Ferreira, M.L. Figueiredo, Paper surface chemistry as a tool to improve inkjet printing quality, BioResources, 6 (2011) 4259-4270.

[17] P. Wilson, Size press starch, in: J.M.R. Jerome M. Gess (Ed.) The Sizing of Paper, Tappi Press, Atlanta, 2005, pp. 249-256. 
[18] R. Carceller, A. Juppo, New surface size composition changes paper surface properties for improving ink jet printability of copy paper, Paperi ja Puu/Paper and Timber, 86 (2004) 161-163.

[19] R.L. Kearney, Starch, in: J.M.R. Jerome M. Gess (Ed.) The Sizing of Paper, Tappi Press, Atlanta, 2005, pp. 237-248.

[20] C.W.H. John A. Lloyd, The determination of fibre charge and acidic groups of radiata pine pulps, Nordic Pulp \& Paper Research Journal (NPPRJ), 8 (1993).

[21] G. Carlsson, J. Van Stam, Interactions between charged latex colloids and starch polyelectrolytes studied by fluorescence microscopy with image analysis, Nordic Pulp and Paper Research Journal, 20 (2005) 192-199.

[22] I.M.T. Moutinho, P.J.T. Ferreira, M.L. Figueiredo, Impact of surface sizing on inkjet printing quality, Industrial and Engineering Chemistry Research, 46 (2007) 6183-6188. 